\title{
A gamified approach towards identifying key opportunities and potential sponsors for the future of F1 racing in a declining car ownership environment.
}

\author{
Evangelos Markopoulos ${ }^{1}$, Panagiotis Markopoulos ${ }^{2}$, Mika Liumila ${ }^{3}$, Younus Almufti ${ }^{1}$, \\ Chiara Romano ${ }^{1}$, Paulina Vanessa Benitez ${ }^{1}$ \\ ${ }^{1}$ HULT International Business School, 35 Commercial Road, Whitechapel, E1 1LD London \\ United Kingdom. \\ ${ }^{2}$ University of the Arts London, Elephant and Castle, SE1 6SB, London, \\ United Kingdom. \\ ${ }^{3}$ Turku University of Applied Science, Joukahaisenkatu 3, 20520, Turku, Finnland. \\ evangelos.markopoulos@faculty.hult.edu,p.markopoulos1@arts.ac.uk, \\ mika.luimula@turkuamk.fi, yalmufti2015@student.hult.edu, cromano2015@student.hult.edu, \\ paubenitez2015@student.hult.edu
}

\begin{abstract}
This research work aims to propose new approaches towards identifying key opportunities and potential sponsors for the future of F1 racing in an environment with declining car ownership, without resorting to endless licensing agreements. The paper presents a gamification approach on which an innovative and disruptive operations framework can be developed to help, without operational complexity and commitment, F1 teams gain new customers (fans) and recapture essential markets and targets groups. The paper also contributes on establishing a base for effective strategy development based on the user's/player's engagement and behavior. Furthermore, this work extends towards the analysis of the game's operations and the marketing initiatives needed to succeed. The proposed approach varies from $\mathrm{OHH}$ (out of home advertising), interactive marketing, celebrities, F1 drivers' endorsements, and other related supportive initiatives such as search engine optimization on online research platforms and other promotion and marketing dissemination initiatives.
\end{abstract}

Keywords: Gaming · Gamification · Serious Games · esports · Entertainment Games $\cdot$ Monetization $\cdot$ Sponsorship $\cdot$ F1 $\cdot$ Formula $1 \cdot$ Blue Ocean Strategy

\section{$1 \quad$ Introduction}

F1 (Formula One) can be considered as one of the most attractive, challenging but also most expensive sports in the world. The F1 industry can be seen as a multidisciplinary area which integrates finance, business management, marketing, technology, innovation, manufacturing, material engineering, and many more. The overall cost and complexity of operations of the glamorous and amazing world of F1 constantly increases while the fans and followers decrease. This situation results to the decrease of 
interest and increase of the risk on the viability of the sport which extends much beyond racing.

This research work aims to propose new approaches towards identifying key opportunities and potential sponsors for the future of F1 racing in an environment with declining car ownership without resorting to endless licensing agreements. The paper presents a gamification approach on which an innovative and disruptive operations framework can be developed that can contribute to F1 teams on gaining new customers (fans), recapture essential markets and targets groups, without operational complexity and commitment. The paper can also contribute on establishing a base for effective strategy development based on the user's/player's engagement and behaviour.

The proposed approach utilizes the F1 history though its drivers, manufacturers and time periods, to bring up the wealth of memories, emotions, but also challenges, needed towards reinventing a sponsorship model for all type of organizations involved in the operations of F1. To illustrate this approach a game called 'F1 Legends' has been designed and supported with the operations activities needed for successful strategy execution on sponsors engagement. The proposed model can be adopted by any F1 organization seeking such benefits. The game can also be customized as a different game for different organizations such as the 'Ferrari Legends', the McLaren Legends' the 'Williams Legends' etc. The same concept can also be adapted by the F1 sponsors who support the sport at different times. In such a case the game can be called the 'Shell Legends', the 'Marlboro Legends', etc., where the F1 car becomes the legend of the sponsor.

The overall framework of the gamification approach, which can be execute via an on-line platform, can increase brand awareness and interest of younger audiences, and provide access to emerging and gaming friendly markets where F1 records low popularity. The game emphasizes on providing a highly innovative online platform using competitive racing among players, tournaments with high rewards and ladder boards, in an attempt to operate as an eSport open to all kind of players and not necessarily to the professional games. The paper extends towards the analysis of the game's operations and the marketing initiatives needed to succeed. The proposed approach varies from $\mathrm{OHH}$ (out of home advertising), interactive marketing, celebrities, F1 drivers' endorsements, and other related supportive initiatives such as search engine optimization on online research platforms and other promotion and marketing dissemination initiatives.

\section{The e-Sports gaming phenomenon.}

The e-sport industry had been invented since the arcade era, however esports did not become mainstream until very recently. The worldwide phenomenon of esports had a quite humble start with simple tournaments hosted around arcade machines by the amateur players of that period. The evolution of the esports over the time was achieved with a predictable slow pace related to the development of the gaming industry, until the introduction of the multiplayer games with Quake to be considered as the first competitive game with multiplayers. The very first unofficial esports tournament took place on 1972 with the Space Invaders game, and the first official esports tournament was on 1997 with the Red Annihilation Quake game. 
The advancement from the first competition to what eSports are considered today is tremendous. Esports will soon be a billion-dollar business sector and a global audience of over 300 million fans [1]. In 2018 the revenue from esports only in North America reached the $\$ 345$ million (fig. 1).

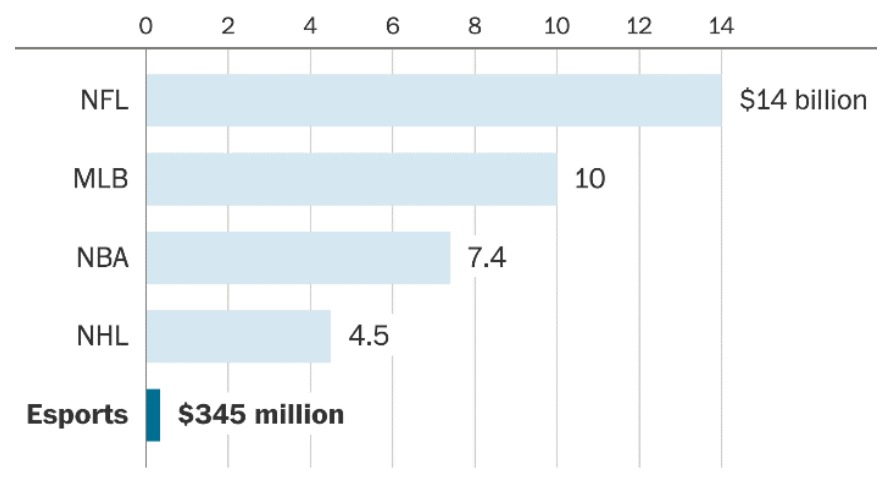

Fig. 1. Annual revenue for esports (North America only) and US major league sports,

Tremendous growth is also indicated at the esport prize money. Today esport athletes surpass what established sports provide to their athletes. The champions of the DOTA-2 International received in 2018 the amount of 25.5 million\$ (fig.2) [2]. The total prize pools for selected esports and traditional sports tournaments indicate a significant drive in the growth of the esports.

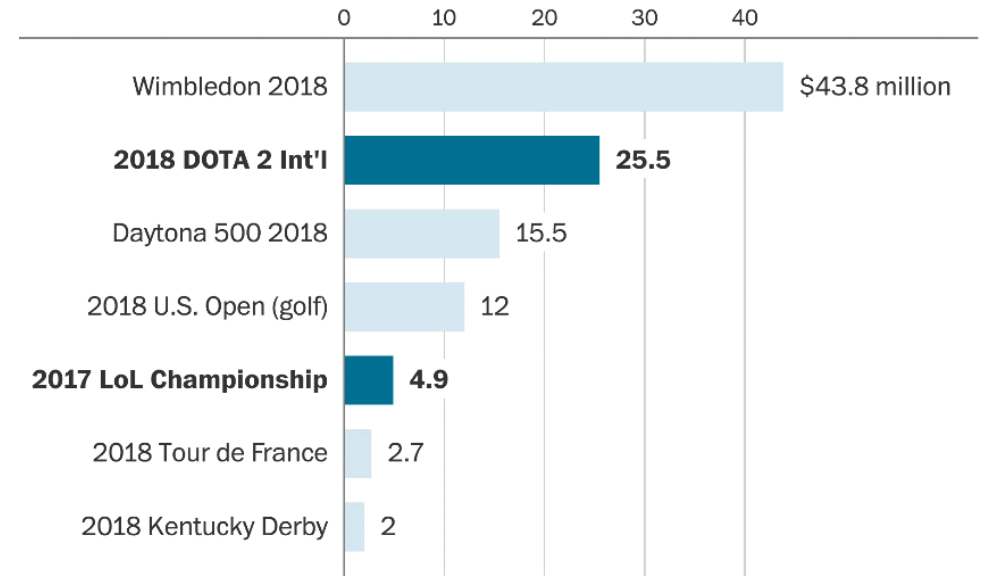

Fig. 1. Prize money at esports.

The growth of esports extend also to the followers they have. Over the time the amount of people interested in competitive games grew significantly, and in turn the esport industry grew as well. The grabbing eyeballs on esports has gone beyond expectations reaching 106.2 million only on the 2017 championship (fig.3). 


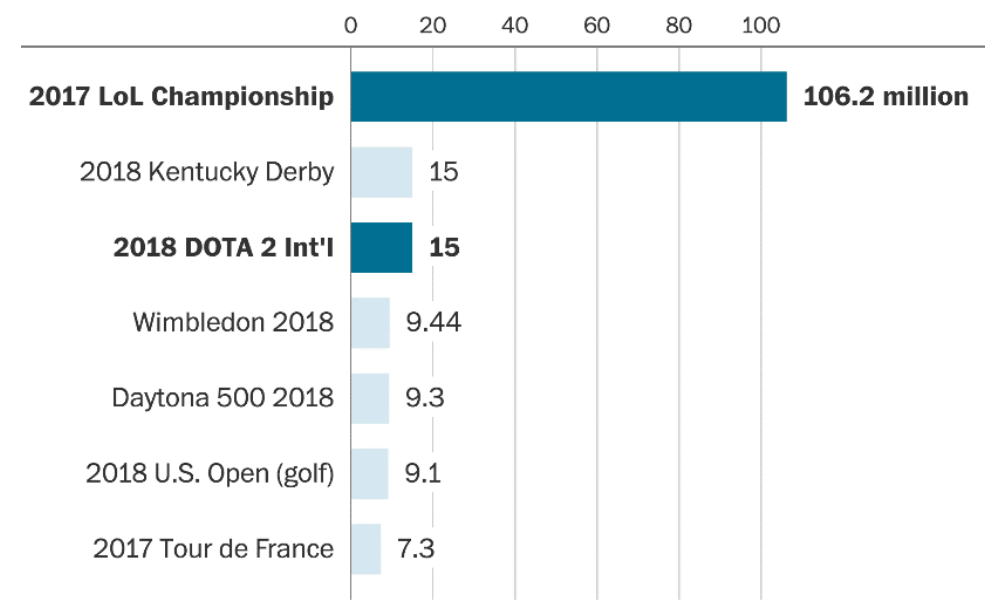

Fig. 3. Peak viewers of selected esports and traditional sport tournaments.

Esports radically redefined the terms 'athlete' and 'sport'. The idea of a virtual athlete has become a reality with the U.S. government giving P1 Visa to esports professionals and recognizing them as professional athletes. South Korea is also a leading county in professional video game competitions, calling them esports, by creating organized leagues, training well-financed professional teams and filling giant stadiums with frenzied fans to cheer on their favorite players [3].

With gaming becoming a trend in recent years more people express interest in esports as they prefer to see professional players play their favourite games. The ranking system in most games also helps the popularity of esports since professionals and casual players can play on the same ranking ladder with the only difference between them to be purely their skills and strategy.

\section{3 eSports as a Blue Ocean Strategy}

The term blue ocean and blue ocean strategy has been invented by W. Chan Kim and Renée Mauborgne as a marketing theory which presents strategic moves that can create a leap in the value of an organization, its buyers, employees, while generating new demands by making the competition irrelevant. The term practically reflects to the name itself as Blue Ocean are new markets while red oceans are saturated markets [4]. The key characteristics of the blue ocean is summarized in table 1.

Table 1. Blue and Red Ocean strategy characteristics.

\begin{tabular}{ll}
\hline Blue Ocean Strategy & Red Ocean Strategy \\
\hline Compete in existing market space & Create uncontested market space \\
Beat the competition & Make the competition irrelevant \\
Exploit existing demand & Create and capture new demand \\
Make the value-cost trade-off & Brake the value-cost trade-off
\end{tabular}




\begin{abstract}
Align the whole system of a firm's Align the whole system of a activities with its strategic choice firm's activities in pursuit of difof differentiation or low cost. ferentiation and low cost.
\end{abstract}

The threats and opportunities of going blue are quite similar in any industry even and they could not be different for the gaming industry and the esports as well. However there have been games that evolved into esports with significant success, audiences and impact to the economy band the society.

'League of Legends' (LoL) is one example which created a gaming blue ocean and turned out to be one of the most popular games in the world of esports. LoL is a MOBA (Multiplayer Online Battle Arena) type of game, where MOBA is an extremely popular game mode. LoL started simply as a community made mod known as 'Defense of the Ancients' (DotA) for a strategy game called 'Warcraft 3'. However 'League of Legends' was the first true MOBA game which created a blue ocean to the gaming industry via MOBAs. LoL rose to popularity amongst gamers very fast as it was free, it was a computer game able to run on most systems and because it have a very competitive nature. That same competitive nature turned it in to an esport with the most followers in the world (fig. 4). The game increased its player base from 12 million in 2011 to 119 million in 2017 [5], [6].

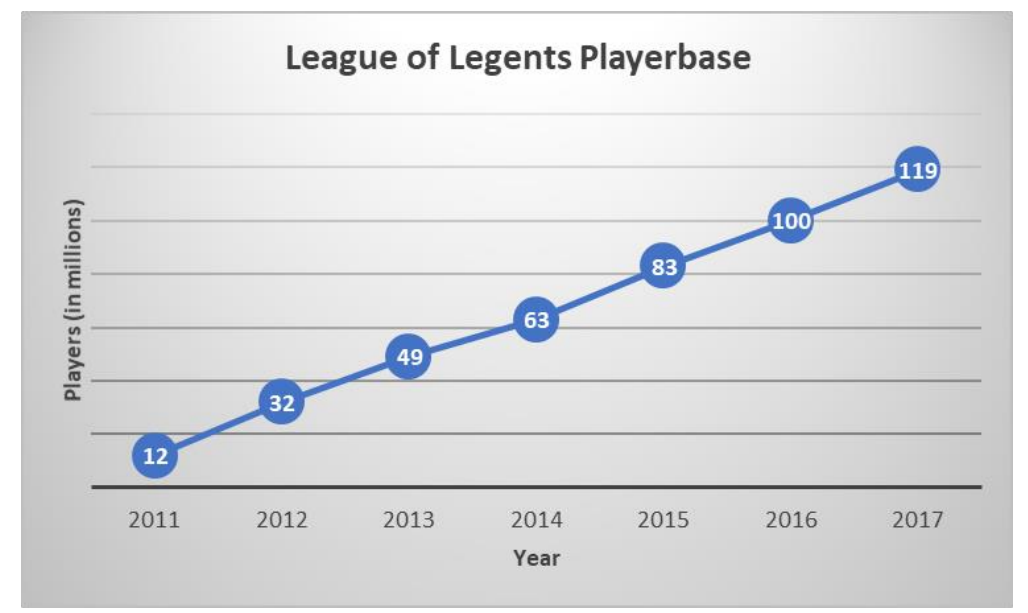

Fig. 4. League of Legend player base increase.

eSports can certainly lead to blue oceans but there are pre and post conditions that need to be satisfied towards achieving and sustaining this goal.

One of the preconditions is the popularity of the game before entering the esport challenge. In the League of Legends example there were many factors that helped but its popularity was a significant one. Even upon release the game LoL had already a decent player base mostly from the DotA fans, ready to download and play it. While the tournaments started the small but loyal fanbase kept promoting the game. The game developers also encouraged the momentum of the fans by adapting a referral system that was rewarding players with in-game awards. Most successful esports derived from companies with very loyal followers, such as Blizzard, otherwise the effort and time 
needed to reach the top of the list is massive that can turn the overall attempt and investor very risky

\section{$4 \quad$ The F1 economics.}

Formula One (F1) began in the early 1920 as the European Grand Prix till the late 1930's. The concept evolved to Formula One with the Fédération Internationale de l'Automobile's (FIA) which standardized the competition and racing rules. A few years later, in 1950, the competition was named World Championship of Drivers and the first race took place at Silverstone. The term Formula One is composed with 'Formal' meaning the 'set of rules and regulations drivers have to deal with', and the 'One' meaning the top category of racing.

Since then, Formula One has evolved into a very impressive bur also expensive sport. The cost of keeping Formula One's wheels turning has been revealed in 2018 from the financial statements of 10 teams, indicating the total annual spend of $\$ 2.6$ billion. [7]. However profitability is marginal for only a few teams while most of them recorded loses. Figure 5 indicates the spending per team for 2016.

\section{F1 TEAM FINANCES}

\begin{tabular}{|l|l|l|l|}
\hline & Revenue & Costs & Net profit/loss \\
\hline Ferrari* & $£ 382.0 \mathrm{~m}$ & $-£ 464.0 \mathrm{~m}$ & $-£ 82.0 \mathrm{~m}$ \\
\hline Force India Formula One Team & $£ 81.4 \mathrm{~m}$ & $-£ 109.1 \mathrm{~m}$ & $-£ 11.6 \mathrm{~m}$ \\
\hline Haas Formula & $£ 100.0 \mathrm{~m}$ & $-£ 94.9 \mathrm{~m}$ & $£ 4.1 \mathrm{~m}$ \\
\hline Haas Formula Italia & $£ 6.9 \mathrm{~m}$ & $-£ 6.2 \mathrm{~m}$ & $£ 0.4 \mathrm{~m}$ \\
\hline McLaren Racing & $£ 190.3 \mathrm{~m}$ & $-£ 193.6 \mathrm{~m}$ & $-£ 3.2 \mathrm{~m}$ \\
\hline Mercedes-Benz Grand Prix & $£ 289.4 \mathrm{~m}$ & $-£ 275.1 \mathrm{~m}$ & $-£ 3.8 \mathrm{~m}$ \\
\hline Mercedes AMG High Performance & $£ 140.4 \mathrm{~m}$ & $-£ 126.9 \mathrm{~m}$ & $£ 1.5 \mathrm{~m}$ \\
\hline Powertrains & & & \\
\hline Red Bull Technology & $£ 247.8 \mathrm{~m}$ & $-£ 238.1 \mathrm{~m}$ & $£ 8.4 \mathrm{~m}$ \\
\hline Renault Sport Racing (UK) & $£ 119.1 \mathrm{~m}$ & $-£ 121.0 \mathrm{~m}$ & $-£ 3.3 \mathrm{~m}$ \\
\hline Renault Sport Racing (France) & $£ 191.1 \mathrm{~m}$ & $-£ 197.5 \mathrm{~m}$ & $-£ 8.8 \mathrm{~m}$ \\
\hline Sauber Motorsport** & $\mathrm{n} / \mathrm{a}$ & $\mathrm{n} / \mathrm{a}$ & $\mathrm{n} / \mathrm{a}$ \\
\hline Scuderia Toro Rosso & $£ 127.3 \mathrm{~m}$ & $-£ 124.8 \mathrm{~m}$ & $£ 1.5 \mathrm{~m}$ \\
\hline Williams Grand Prix Engineering & $£ 177.7 \mathrm{~m}$ & $-£ 170.8 \mathrm{~m}$ & $£ 5.9 \mathrm{~m}$ \\
\hline TOTAL & $£ 2,053.4 \mathrm{~m}$ & $-£ 2,122.0 \mathrm{~m}$ & $-£ 90.9 \mathrm{~m}$ \\
\hline
\end{tabular}

* All data is derived directly from 2016 financial statements, except in the case of Ferrari which is only partially derived from financial statements.

** Sauber is based in Switzerland and therefore does not file publicly available accounts.

Fig. 5. Formula One team finances.

The F1 economics in terms of costs can be categorized on the component costs of formula one cars, the sponsorship cost per area on a car, and the team budget operations.

Figure 6 indicates the 2015 cost of a formula one car, to be $£ 6$ million on an average, with the gearbox cost at $£ 750.000$, the exhaust $£ 172.000$, the frond wing $£ 150.00$, the brakes $£ 149.000$, and even the steering wheel at $£ 50.000$, among the rest.

The main revenue stream of the $\mathrm{F} 1$ comes from the sponsorships. The total revenue that can be generated from sponsorships on a car can be $£ 66.7$ million on an average (shown in fig. 7), with the sponsorships on the airbox, sidepod and rear wind to be at 
$£ 17$ million each [8]. The revenues from the sponsors are 11 times more than the cost of a car, but it is not enough to cover the overall operations of an F1 team.

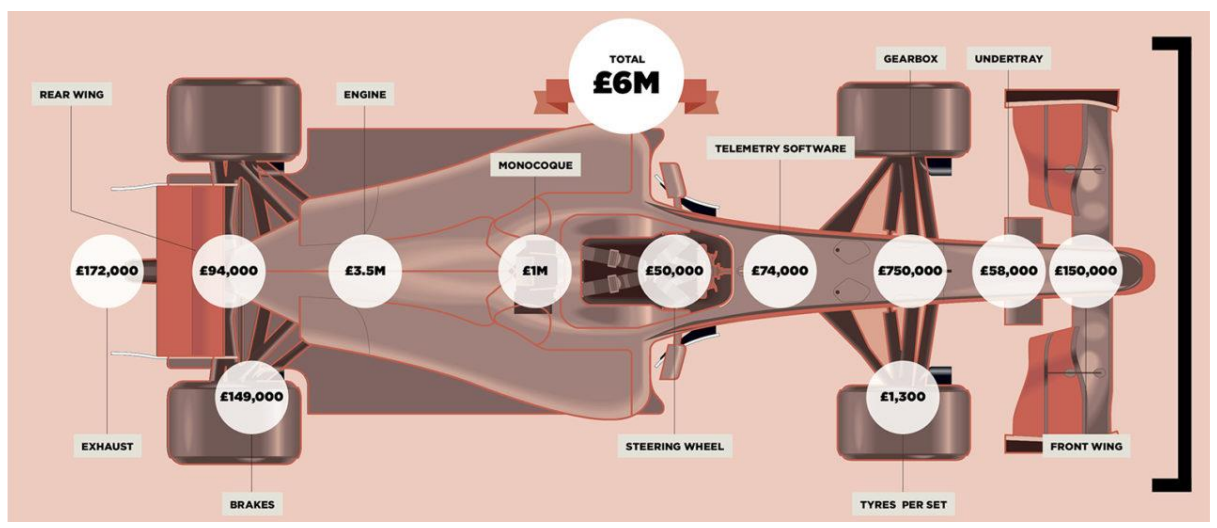

Fig. 6. Component cost and total cost of a Formula One car

The cost for the total operations of an F1 team can reach the $£ 158$ million. From this, the research and development costs are nearly $£ 41$ million, the salaries $£ 42$ million, the production $£ 39$ million, and the operations $36 £$ million.

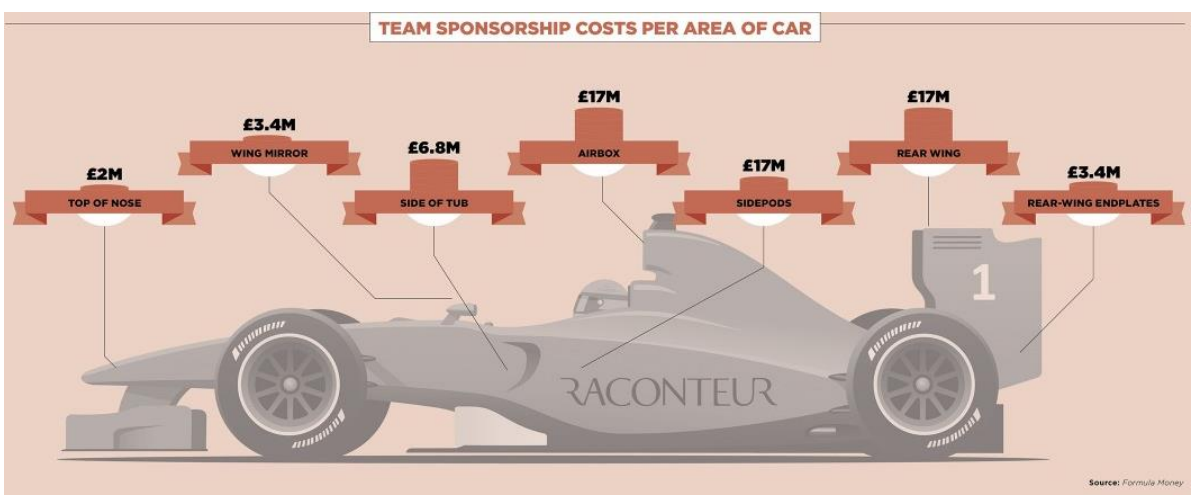

Fig. 7. Sponsorship costs per area on a Formula One car

\section{$5 \quad$ The F1 esports Blue Ocean.}

With marginal profits for a few F1 teams, but mostly loses for the rest, it becomes difficult to foresee the future of F1. New business strategies and ecosystems need to be developed to link the traditional sport activity with the eSport concept, expanding the follower and sponsors base, after all both types of the sport can learn from each other. Biathlon is an example of such an approach which combined the actual biathlon with mobile gaming [9]. Players were allowed in Biathlon X5 game to participate in a 
real-world competition hosted by International Biathlon Union World Championships 2015 and compete with other players in the same time (fig. 8).

This application consisted of two modes namely "Play Live" and "Play Now". The first one could be played only when the real-world competition was in progress.

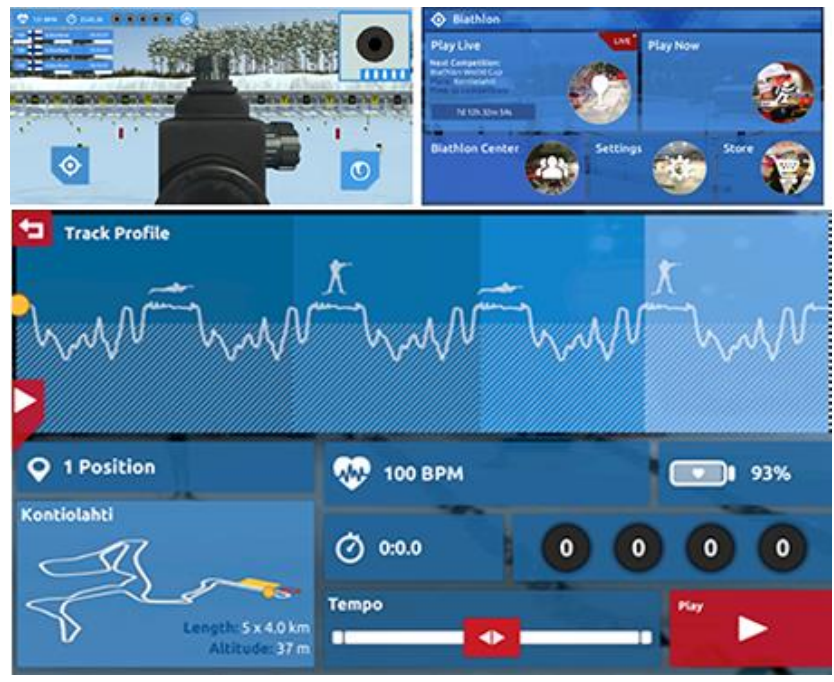

Fig. 8. Screenshots from the Biathlon X5 game.

In this project, we learned that this type of combination of real-life sport and gaming can be seen as an ecosystem consisting of various screens and applications to be used in the same time while watching or actually participating in the competition. In the F1 case spectators have already various screens which can be chosen based on everyone's preferences. Therefore it is possible that experiences collected in IBU World Championships can be utilized in the F1 gaming sponsorship engagement as well, but there are challenges on that. In esports the requirements to create a blue ocean are not only related with the innovation of the new product or service and the market it will serve but also on the followers that can attract which will form the critical mass for effective operations and return on the investment.

Strategy games, First-person shooters, Fighting, and MOBAs are the common game genres featured in esports. However, a game genre that is very popular but was completely absent from the world of esports is racing games. Up until recently, racing game competitions had limited followers without attracting the attention of the average viewer, but lately this is starting to change. Project CARS managed to become the first proper racing game esport. The game attracted the attention of many prestigious car manufacturers such as McLaren, Renault, Ginetta and others, and hosts collaborative esport tournaments with them. [10]. Further more the McLaren Shadow esport competition provides a leading and inspirational structure as incentive for the players and the followers [11]. Though the McLaren Shadow Project the company searches for the brightest and the best racing talent in esports, for the next phase in McLaren's esports strategy [12]. 
It appears that the era for racing sports has moved into a different dimension. Methods and practices have been successfully applied, popularity is growing and the leading car manufactures are seriously engage in it. Racing game fans who are very often fans of real cars and real racing events have the opportunity to enjoy more from the connection of the esport to the real sport.

\section{A multiplayer eSports Gamification Approach for achieving F1 sponsor's engagement.}

Racing esports can increase the followers of a the car manufacturers and the overall followers of the competitions they are take part of. Esports, and specifically in the F1 can contribute in sponsor engagement which can be translated into economic relief for the F1 teams. Such a sponsor engagement oriented approach can be achieved with the development of an online multiplayer Formula One game. This proposed solution is targeted not only to achieve new sponsorships for F1 but also to expose the sports to new and younger age groups. Creating a popular game is an efficient way to reach millennials and generate a strong brand connection with them. The proposed game enables F1 teams to create a large portfolio of virtual sponsorships and apply direct and indirect marketing practices.

The architecture of such a game has been developed and various allocated areas for sponsorships have been included that can increase the overall revenue streams. The game has been designed to have two modes. The first one is a multiplier mode which consists competitive online races and a levelling up system that unlocks stages and elements after the user completes part of the marketing campaign. The second one is the campaign mode and has been designed to assure brand awareness for the F1 team as it revolves around the history of the team.

The multiplayer mode provides a strong sponsorship model that supports the exposure for the sponsors in a consistent manner the same way it they get in the actual sport. Furthermore, the player gains benefits from tournament participation while playing a competitive experience that is monitored by the F1team itself.

The game can support F1 teams to achieve more sponsors with the method of unlockable items and screens loading. Unlockable are the items a player can use to personalize his/her car and driver (only for aesthetic purposes) and to differentiate themselves from other drivers. The player obtains these through playing the campaign, leveling up the driver, winning a tournament or by purchasing various game elements or abilities with actual currencies or game currency. All unlockable elements can be sponsored and contain different rarities according to the cost of the sponsorship. On the other hand, loading screens are used on idle time for the player. The game has four different loading screens displayed when the player race is loading. The loading screens can promote and utilize best the legend of the car manufacturer along with a sponsor.

In order to increase awareness and engage more sponsorships, the game is designed to be played through frequent tournaments where sponsors can change on each. Different unlockables are available per tournament and per sponsor. The scenery of the race includes potential sponsors as well. Along the racetrack the game provides various billboards and signs available for sponsors. Cities and countries can also sponsor F1 to have the races simulated in their location. Campaign and cutscenes have been designed 
for more sponsorships opportunities. When a player meets a campaign milestone a cutscene appears with a paid sponsor. The races offered in this game can also be sponsored along with a variety of other game before, during and after the race. The sponsorship process can be customized based on the items, tournaments and frequency the sponsor desires to appear in various elements or races.

\section{$7 \quad$ Sponsorship benefits through gaming platforms}

Gaming platforms can provide the base for multidimensional sponsorship practices in product awareness and branding which can be repeated over time intervals with different players and on different target groups. Some of the benefits that can be achieve with such an approach are briefly listed:

Increase consumer loyalty: Customer, loyalty and trust can be generated due to the exposure a brand has with such sponsorship strategy.

Generates awareness: Promotion in alternative and interactive ways, different from traditional marketing campaigns, helps the public to learn in detail the brand, its values, identity and objectives, and develop activities that makes the brand more identifiable.

Reach new target groups : Games can reach larger and specific target globally with less effort needed for the conventional marketing campaigns.

Improved brand positioning: sponsorship is a good way to improve branding and thereby improve positioning among the same target, as well as among its competitors.

Spread the publicity "by word of mouth": Innovatively interactive and immersive games create fans only with a 'thumbs up'.

Promotion of sales: Direct and indirect sales or brand promotions during the various stages of the game.

Motivate B2B marketing: New business relationships or strategic alliances with sponsors are formulated.

Encourages engagement: Consumers can feel part of the brand. The sponsor generates engagement with the client and within the company and therefore the sense of belonging is transmitted to the target.

\section{Risks and considerations. SWOT and BCG Matrix analysis.}

In essence, a SWOT examination is intended for consistency of clear and shrouded factors that may impact a proposed strategy. By analyzing the proposed approach through SWOT, potential challenges will be evaluated in order to be resolved.

According to Grand View Research, Inc., the video game industry will grow by 171.96 billion USD by 2025 [13]; therefore, by taking advantage of the statistics, the proposed online game will be able to provide F1 a new strategy to gain sponsors.

Regarding the strengths, F1 has an excellent worldwide audience of more than 550 million; hence, it already has a strong brand identity which can help the game be recognized faster than other less known competitors. Furthermore, the game is proposed to be launched in the market with a freemium pricing strategy, which consists in providing the service without any charge; however, fees can still be charged for extra highlights, features, or virtual products. The game also provides weekly tournaments which 
can have a different sponsor every week on all elements. These strengths generate the opportunities for potentially new and more sponsor engagement. On the other hand, weaknesses can be considered the high cost to develop the game and the users' expectations that might be higher from what can be launched on version 1.0. This could lead to possible threats that the game might face, such as not having enough users to attract the sponsors.

Placing the characteristics presented in the SWOT analysis into a Boston Consulting Group growth-share matrix, the proposed approach would be considered as a Question mark. With a high market growth in the fast-growing esports sector, but low market share in the interest of F1 in the esports, the proposed approach is capable for the best which can be the fast adaptation, and the worse which is low adaptation. However, the market does exist and the opportunities are open.

\section{$9 \quad$ Areas of further research.}

The proposed approach to address a key issue of the F1 market is a simplified way to resolve sponsorship-oriented challenges based on awareness and dissemination of the manufacture's brand at new target groups. The way gamification is introduced in this case aims to demonstrate its application in an integration of serious and entertainment scope of games. The research will be extended with the development of a fullscale game hopefully with the participation of an industry manufacturer in order to adjust it into to actual needs, targets and goals. This will provide reliable metrics that can validate the effectiveness of the proposed approach in the real market and under real conditions with a real partner. The outcome of such progress will generate results that can be published and impact the way new sponsorship models can be achieved for gamified products and strategies in very niche markets.

Applied gamification for economics and sponsorship engagement are research areas that can grow together. Such an integration can provide financial, development and operations models that can contribute to the adaptation of gamification as an effective strategy and approach in F1 and not only.

\section{Conclusions.}

As firms extend their operations into global markets, it is becoming increasing apparent that they have to create high levels of brand awareness which can contribute towards higher revenues and profit margins. Additionally, with increasing competition in most industries, firms are compelled to adopt relative strategies aimed to differentiate themselves from competitors and to better connect and form relationship bonds with their target audiences.

Serious games and corporate gamification can be considered more of a strategy than a technology. The adaptation of such strategies can be applied even in the most niche markets. F1 is a very conservative industry to anything that is not directly related with the car, the engineering performance it represents and the driver of course. However the sport if facing a clear decline on its followers while the operation costs increase. 
The need for alternative sponsorship models is very important for the viability of the sport and the overall economy build around it.

The introduction of gamification is an approach to resolve the challenge of achieving new sponsor funding by involving a new customer base. The young generation and the tech generation compose a significant part of the worlds population which needs their own communication channels to engaged not only in F1 but in anything that needs their attention. The proposed approach creates a new customer base for the F1 sponsors without the direct involvement of the $\mathrm{F} 1$ in it. It utilizes the history, the records and the brand F1 still has, in order to flip the fan group, revitalize its existence, and be applied in other similar industries such as the automotive sector, aerospace, defense etc. Gamification has no limits on the industry as it exists to create the pleasure of exploration while unconsciously contributes towards achieving corporate and organizational strategic goals.

\section{References}

1. World Economic Forum. The explosive growth of eSports, https://www.weforum.org/agenda/2018/07/the-explosive-growth-of-esports/

2. The Washington Post. The massive popularity of esports, in charts, https://www.washingtonpost.com/business/2018/08/27/massive-popularity-esports-charts/?noredirect $=$ on\&utm term $=.2757$ af149d10

3. The New York Times. For South Korea, E-Sports Is National Pastime, https://www.nytimes.com/2014/10/20/technology/league-of-legends-south-korea-epicenter-esports.html

4. Kim, W.C. and Mauborgne, R.: Blue Ocean Strategy: How to Create Uncontested Market Space and Make the Competition Irrelevant. Boston: Harvard Business School Press. (2004)

5. Is League of Legends Finally Dying In 2019, https://www.lol-smurfs.com/blog/is-league-oflegends-dying/ )

6. Forbes. Riot Games Reveals 'League of Legends' Has 100 Million Monthly Players, https://www.forbes.com/sites/insertcoin/2016/09/13/riot-games-reveals-league-of-legendshas-100-million-monthly-players/\#5a9a5a45aa8b

7. The \$2.6 Billion Budget That Fuels F1's 10 Teams, https://www.forbes.com/sites/csylt/2018/04/08/revealed-the-2-6-billion-budget-that-fuelsf1s-ten-teams/\#240e 71 cc6595

8. Raconteur. The Economics of Formula 1, https://www.raconteur.net/infographics/the-economics-of-formula-1

9. Besz, A., Gornicki, M., Heinonen, T., Kiikeri, T., Ratamo, I., Luimula, M., Suominen, T., Koponen, A., Saarni, J., Suovuo, T. and Smed, J.: Three Apps for Shooting Sports: The Design, Development, and Deployment, In: Konstantinos Chorianopoulos, Monica Divitini, Hauge Baalsrud, Letizia Jaccheri, Rainer Malaka (Eds.), Entertainment Computing - ICEC 2015, Lecture Notes in Computer Science 9353, pp. 329-342. Springer, 2015,

10. Project CARS X Ginetta, https://www.projectcarsesports.com/ginetta.html

11. PC2 Project CARS X McLaren, https://www.mclaren.com/formula1/2018/mclaren-shadowproject/

12 McLaren Shadow ProJet: Explained, https://www.mclaren.com/formula1/2018/mclarenshadow-project/mclaren-shadow-project-explained/

13. Grand View Research, Inc., Gaming Market Size Worth $\$ 171.96$ Billion by 2025 | CAGR: 6.5\%: Grand View Research, Inc. PR Newswire: News Distribution, Targeting and Monitoring www.prnewswire.com/news-releases/gaming-market-size-worth-17196-billion-by-2025-cagr-65-grand-view-research-inc-671617663.html. 